\title{
COGNITIVE FUNCTIONAL THERAPY LEBIH BAIK DALAM MENURUNKAN DISABILITAS DARIPADA LATIHAN MCKENZIE PADA PENDERITA NON-SPECIFIC LOW BACK PAIN DI DESA SUNGAI TENDANG
}

\author{
Tri Wahyu Wulandari ${ }^{1}$, Susy Purnawati ${ }^{2}$, Sugijanto ${ }^{3}$, I Nyoman Adiputra ${ }^{4}$, Bagus Komang \\ Satriyasa $^{5}$, Dewa Putu Gede Purwa Samatra ${ }^{6}$ \\ ${ }^{1}$ Program Studi Magister Fisiologi Keolahragaan Universitas Udayana, Denpasar \\ 2,4,5,6 Fakultas Kedokteran Universitas Udayana, Denpasar \\ ${ }^{3}$ Fakultas Fisioterapi Universitas Esa Unggul, Jakarta
}

Email: triustadi@gmail.com

\begin{abstract}
ABSTRAK
Pendahuluan: Non-specific Low Back Pain (NLBP) merupakan nyeri punggung bawah yang tidak dihubungkan dengan patologi spesifik. Terjadinya disabilitas pada NLBP akibat adanya nyeri, imbalance muscle, spasme otot dan perubahan psikologis. Oleh karena itu, dengan adanya pemberian terapi fisik dapat menurunkan nyeri, peningkatan stabilitas dan koreksi postur pada tulang belakang, terapi latihan ini bisa berupa latihan McKenzie dan Cognitive Functional Therapy (CFT). Tujuan Penelitian: untuk mengetahui CFT dapat menurunkan disabilitas dibandingkan dengan latihan McKenzie pada NLBP. Metode: Penelitian ini menggunakan rancangan eksperimental melibatkan sejumlah 20 orang sampel yang merupakan warga Desa Sungai Tendang penderita NLBP berusia 30-60 tahun. Sampel terbagi menjadi 2 Kelompok secara acak sederhana, dimana Kelompok $1(\mathrm{n}=10)$ diberikan CFT dan Kelompok $2(\mathrm{n}=10)$ diberikan latihan McKenzie. Penelitian ini dilakukan 3 kali seminggu selama 4 minggu dengan menggunakan kuesioner penilaian Modified Oswestry Disability Index (MODI). Hasil: Hasil pengujian hipotesis menggunakan paired sample t-test sebelum dan setelah intervensi pada Kelompok 1 dengan nilai $\mathrm{p}$ $<0,0001$ yang berarti bahwa ada perbedaan yang bermakna dari nilai disabilitas sebelum dan setelah intervensi CFT pada NLBP. Pada Kelompok 2 didapatkan nilai $\mathrm{p}<0,0001$ yang berarti bahwa ada perbedaan yang bermakna dari nilai disabilitas sebelum dan setelah intervensi McKenzie pada NLBP. Uji beda disabilitas setelah intervensi antara Kelompok 1 dan Kelompok 2 menggunakan Independent Samples t-test didapatkan nilai $\mathrm{p}=0,001$ dengan rerata setelah pada kelompok 1

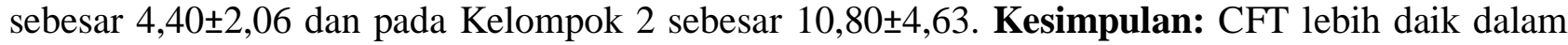
menurunkan disabilitas dibandingkan dengan MK pada penderita NLBP.
\end{abstract}

Kata Kunci: Cognitive Functional Therapy, McKenzie, Non-specific Low Back Pain

\section{COGNITIVE FUNCTIONAL THERAPY IS BETTER THAN MCKENZIE IN REDUCING THE DISABILITY OF NON-SPECIFIC LOW BACK PAIN AT SUNGAI TENDANG VILLAGE}

ABSTRACT

Introduction: Non-specific Low Back Pain (NLBP) is a low back pain that is not associated with specific pathology. Disability in NLBP occurs due to pain, imbalance muscle, muscle spasm and psychological changes. Physical therapy can reduce pain, increase stability and correct posture in the spine with exercise therapy, both are McKenzie exercise and Cognitive Functional Therapy (CFT). Research Objectives: to know that CFT is better exercise to decrease disability than MK with NLBP. Method: This study used an experimental design involving a total of 20 samples who were residents of Sungai Tendang Village, NLBP sufferers aged 30-60 years. The sample was 
divided into 2 simple randomized groups, where Group $1(\mathrm{n}=10)$ was given CFT and Group $2(\mathrm{n}=$ 10) were given McKenzie exercises. This research was conducted 3 times a week for 4 weeks using the Modified Oswestry Disability Index (MODI) assessment questionnaire. Results: The results of hypothesis testing used paired sample t-test before and after the intervention in Group 1 with a $\mathrm{p}$ value $<0.0001$ which means that there is a significant difference from the value of disability before and after CFT intervention on NLBP. In Group 2, a p value $<0.0001$ means that there is a significant difference from the value of disability before and after the McKenzie intervention on NLBP. Different disability test after intervention between Group 1 and Group 2 using the Independent Samples t-test obtained $p=0.001$ with an average after group 1 of $4.40 \pm 2.06$ and in Group 2 of $10.80 \pm 4.63$. Conclusion: CFT is better exercise to decrease disability than McKenzie exercise with Non-specific Low Back Pain.

Keyword: Cognitive Functional Therapy, McKenzie, Non-specific Low Back Pain

\section{PENDAHULUAN}

Salah satu keluhan muskuloskeletal yang sering terjadi dikehidupan sehari-hari yaitu nyeri punggung bawah. Low Back Pain (LBP) merupakan masalah kesehatan dunia yang menyebabkan terbatasnya aktivitas dan juga ketidakhadiran kerja. Nyeri punggung bawah memang tidak menyebabkan kematian, namun menyebabkan individu yang mengalaminya menjadi tidak produktif sehingga akan menyebabkan beban ekonomi yang sangat besar baik individu, keluarga, masyarakat, maupun pemerintah. ${ }^{1}$

Prevalensi LBP di Indonesia sebesar $18 \%$. Angka prevalensi meningkat sesuai dengan bertambahnya usia dan paling sering terjadi pada usia dekade tengah dan awal dekade empat. Penyebab LBP sebagian besar $85 \%$ adalah nonspesifik, akibat kelainan pada jaringan lunak, berupa cedera otot, ligamen, spasme atau keletihan otot. Penyebab lain yang serius adalah spesifik antara lain, fraktur vertebra, infeksi dan tumor. $^{2}$

Nyeri punggung bawah berdasarkkan diagnosis triase, terbagi menjadi 3 kategori, yaitu Specific Spinal Pathologi (fraktur vertebra, tumor, spondyloarthritis, cauda equine syndrome), Ridiculer Syndrome (nyeri radikuler, radiculopathy, spina stenosis) dan Non-specific Low Back Pain (tidak disebabkan oleh patologi spesifik). ${ }^{3}$

Non-specific Low Back Pain (NLBP) merupakan nyeri punggung bawah yang tidak dapat dihubungkan dengan patologi spesifik (cedera traumatis, sprain atau strain lumbar, ketegangan postural dan psikologis). Sedangkan nyeri punggung bawah spesifik mengarah pada suatu proses patologis tertentu seperti infeksi, tumor, osteoporosis, patah tulang belakang lumbar, kelainan struktural, gangguan inflamasi, sindrom radikuler, atau sindrom cauda equine. ${ }^{4}$ Tingginya angka prevalensi ini secara implisit menunjukan pengobatan dan penanganan nyeri punggung harus diperhatikan guna mengembalikan aktivitas fungsional sehari-hari.

Pada kasus NLBP berasumsi bahwa rasa nyeri akan berkembang sesuai dengan riwayat nyeri yang dialami, karena nyeri yang dirasakan hilang timbul dalam waktu yang lama dengan posisi yang berbeda. Hal ini berkaitan dengan biopsikososial, bahwa faktor psikologi maupun psikiatri merupakan prediktor tejadinya pada saat itu juga atau di masa yang akan datang, dan ada korelasi kuat antara depresi dengan tingkat nyeri dan disabilitas pada nyeri punggung bawah. ${ }^{5}$

NLBP dapat mengakibatkan nyeri, imbalance muscle, dan spasme otot sehingga stabilitas otot perut dan punggung bawah mengalami penurunan, terjadi perubahan postur, mobilitas lumbal terbatas, dan mengakibatkan nyeri serta disabilitas pada pasien NLBP. ${ }^{6}$ Oleh karena itu, dengan adanya pemberian terapi fisik pada kasus NLBP sangat dianjurkan untuk penurunan nyeri, peningkatan stabilitas dan koreksi postur pada tulang 
belakang, terapi latihan ini bisa berupa latihan McKenzie dan Cognitive Functional Therapy (CFT).

Intensitas nyeri dapat memengaruhi kondisi fisik, dan juga dapat menimbulkan perubahan terhadap kondisi psikologis dan sosial individu. Aspek psikologis yang mudah dipengaruhi nyeri ini antara lain meliputi aspek kognisi, emosi, kecemasan, depresi, serta kemarahan. Sedangkan aspek sosial dalam bentuk perilaku sosial individu terhadap lingkungannya (menarik diri dan atau menghindari interaksi sosial dengan lingkunganya). Upaya untuk menurunkan nyeri yang disebabkan oleh faktor psikologis melalui salah satu intervensi yang telah terdata secara klinis pada nyeri dan fungsi yang terkait dengan NLBP adalah Cognitive Functional Therapy (CFT). CFT merupakan intervensi perilaku individual yang didasarkan pada prinsip-prinsip biopsikososial yang menantang keyakinan maladaptif dan perilaku disfungsional yang terkait, untuk meningkatkan kontrol nyeri dan membawa pasien kembali ke tujuan mereka untuk bergerak dengan berupa latihan. $^{7}$

Latihan McKenzie merupakan suatu tehnik latihan dengan menggunakan gerakan badan terutama ke arah ekstensi, biasanya digunakan untuk penguatan dan peregangan otot-otot ekstensor dan fleksor sendi lumbosacralis serta dapat mengurangi nyeri. Pemberian terapi latihan berupa McKenzie pada kasus NLBP dianjurkan dengan tujuan untuk peningkatan stabilitas dan koreksi postur pada tulang belakang. Latihan ini diciptakan oleh Robin Mc Kenzie dengan prinsip memperbaiki postur. Sedangkan secara operasional pemberian latihan untuk penguatan otot punggung bawah ditujukan untuk otot-otot ektensor dan untuk peregangan ditujukan untuk otot-otot fleksor punggung. 8

Berdasarkan pemaparan tersebut, maka peneliti ingin membuktikan intervensi Cognitive Functional Therapy lebih menurunkan disabilitas dari pada Mckenzie pada Non-Specific Low Back Pain.

\section{METODE PENELITIAN}

Penelitian ini menggunakan metode eksperimental dengan rancangan penelitian pre-test dan post-test two group design. Kelompok 1 diberikan CFT dan Kelompok 2 diberikan McKenzie. Tes pengukuran disabilitas menggunakan Modified Oswestry Disability Index (MODI).

Penelitian ini di lakukan di Desa Sungai Tendang, Kabupaten Kotawaringin Barat, Kalimantan Tengah, dengan waktu penelitian 4 minggu dan dimulai dari bulan Maret - Mei 2019. Jumlah sampel tiap Kelompok sebanyak 10 orang dan masing-masing Kelompok diberikan latihan 3 kali semingu selama 4 minggu.

Adapun kriteria inklusi dalam penelitian ini adalah Subjek dengan Non-spesific Low Back Pain sesuai dengan assesment fisioterapi, Subjek mengalami keluhan nyeri selama 12 minggu terakhir atau lebih tanpa penyebab patologis, usia antara 30-60 tahun, kooperatif dan bersedia mengikuti program penelitian. Kriteria eksklusi pada penelitian ini adalah kelainan neurologis seperti gangguan sensibilitas dan gangguan saraf motorik, responden mengalami kehamilan, dan pasien yang telah mendapat intervensi dengan modalitas lain.

\section{HASIL PENELITIAN}

\section{Kriteria Subjek Penelitian}

Tabel 1. Distribusi Data Responden

Berdasarkan Usia, Jenis Kelamin dan IMT

Karateristik

Kelompok 1 Kelompok 2

(f) $(\%) \quad$ (f)

(\%)

\begin{tabular}{|c|c|c|c|c|c|}
\hline \multicolumn{6}{|l|}{ Usia } \\
\hline & 31-40 Tahun & 3 & 30 & 1 & 10 \\
\hline & 41-50 Tahun & 4 & 40 & 7 & 70 \\
\hline & 51-60 Tahun & 3 & 30 & 2 & 20 \\
\hline \multicolumn{6}{|c|}{ Jenis Kelamin } \\
\hline & Laki-laki & 4 & 40 & 3 & 30 \\
\hline & Perempuan & 6 & 60 & 7 & 70 \\
\hline \multicolumn{6}{|l|}{ IMT } \\
\hline & Normal & 2 & 20 & 5 & 50 \\
\hline & Overweight & 8 & 80 & 5 & 50 \\
\hline
\end{tabular}


Tabel 1 di atas menunjukkan data umum karakteristik sampel penelitian yang terdiri dari: usia, jenis kelamin, IMT. Usia terbanyak berada pada rentang usia 41-50 pada ke dua Kelompok, perempuan merupakan frekuensi terbanyak dibandingkan frekuensi laki-laki pada ke dua Kelompok, dan hasil IMT terbanyak ada di kategori overweight pada Kelompok 1 sedangkan pada Kelompok 2 memiliki nilai kategori yang seimbang antara overwight dan nomal.

\section{Uji Normalitas dan Uji Homogenitas}

Tabel 2. Nilai p Hasil Uji Normalitas dan Homogenitas

\begin{tabular}{|c|c|c|c|}
\hline \multirow[t]{2}{*}{ Variabel } & \multicolumn{2}{|c|}{$\begin{array}{c}\text { Uji } \\
\text { Normalitas } \\
\text { dengan } \\
\text { Shapiro Wilk } \\
\text { Test }\end{array}$} & \multirow{2}{*}{$\begin{array}{c}\text { Uji } \\
\text { Homogenitas } \\
\text { (Levene's Test) }\end{array}$} \\
\hline & $\begin{array}{c}\text { Kel. } \\
1\end{array}$ & $\begin{array}{c}\text { Kel. } \\
2\end{array}$ & \\
\hline $\begin{array}{l}\text { Disabilitas (Sebelum } \\
\text { Intervensi) }\end{array}$ & 0,442 & 0,835 & 0,772 \\
\hline $\begin{array}{l}\text { Disabilitas (Setelah } \\
\text { Intervensi) }\end{array}$ & 0,191 & 0,543 & \\
\hline Disabilitas (Selisih) & 0,081 & 0,799 & \\
\hline
\end{tabular}

Berdasarkan Tabel 2, keseluruhan data memiliki nilai $p>0,05$ dan menunjukkan data dari masing-masing kelompok memiliki berdistribusi normal. Sehingga uji hipotesis yang digunakan adalah uji parametrik. Uji Homogenitas didapatkan nilai $p=0,772(p>$ $0,05)$ yang menunjukkan data homogen pada sebelum intervensi.

\section{Uji Beda Rerata Disabilitas pada Masing Masing Kelompok}

\section{Tabel 3. Hasil Analisis Data dengan Paired} Sample t-test

\begin{tabular}{lccc}
\hline & $\begin{array}{c}\text { Sebelum } \\
(\text { Rerata } \pm \text { SD })\end{array}$ & $\begin{array}{c}\text { Setelah } \\
(\text { Rerata } \pm \text { SD })\end{array}$ & Nilai p \\
\hline Kelompok 1 & $40,40 \pm 5,79$ & $4,40 \pm 2,06$ & 0,000 \\
Kelompok 2 & $40,40 \pm 7,04$ & $10,80 \pm 4,63$ & 0,000 \\
\hline
\end{tabular}

Berdasarkan Tabel 3 diatas, hasil uji hipotesis pada Kelompok 1 didapatkan nilai $p$ $<0,001$, hal ini dapat disimpulkan bahwa ada perbedaan yang bermakna dari disabilitas sebelum dan setelah intervensi CFT pada NLBP. Sedangkan pada Kelompok 2 didapatkan nilai $p<0,001$, hal ini dapat disimpulkan bahwa ada perbedaan yang bermakna dari disabilitas sebelum dan setelah intervensi McKenzie pada NLBP.

\section{Uji Komparasi Setelah Intervensi Disabilitas pada Kedua Kelompok}

Tabel 4. Hasil Analisis Data Disabilitas dengan Independent Sample t-test

\begin{tabular}{ccc}
\hline & $\begin{array}{c}\text { Sebelum } \\
(\text { Rerata } \pm \text { SD })\end{array}$ & $\begin{array}{c}\text { Setelah } \\
(\text { Rerata } \pm \text { SD })\end{array}$ \\
\hline Kelompok 1 & $40,40 \pm 5,79$ & $4,40 \pm 2,06$ \\
Kelompok 2 & $40,40 \pm 7,04$ & $10,80 \pm 4,63$ \\
\hline Nilai p & 1,000 & 0,001 \\
\hline
\end{tabular}

Berdasarkan Tabel 4 menunjukkan bahwa pada data sesudah pelatihan nilai $\mathrm{p}=0,001(\mathrm{p}<$ $0,05)$. Hal ini menunjukkan adanya perbedaan yang signifikan pada Kelompok 1 (Cognitive Functional Therapy) dan Kelompok 2 (McKenzie). Pada Kelompok 1 terjadi penurunan disabilitas ditemukan rerata sebesar $88 \%$, sedangkan pada Kelompok 2 terjadi penurunan disabilitas ditemukan rerata sebesar 73\%. Hal tersebut menunjukkan penurunan disabilitas dari ke dua Kelompok yang memiliki efek lebih besar yaitu pada Kelompok 1.

\section{PEMBAHASAN}

Efek Cognitive Functional Therapy dalam menurunkan disabilitas pada Non spesific Low Back Pain

Cognitive Functional Therapy (CFT) memiliki komponen utama dalam menurunkan disabilitas pada NLBP, sehingga individu mampu dalam manajemen nyeri dan 
keterbatasan fungsionalnya. Komponen dalam intervensi CFT yang pertama yaitu making sense of pain, dalam komponen kognitif ini dapat membantu pasien untuk memahami rasa sakit mereka berdasarkan faktor multidimensi yang diidentifikasi dalam wawancara dan pemeriksaan klinis, kemudian mengenai keyakinan yang tidak membantu dihilangkan dan tujuannya untuk perubahan perilaku yang disepakati. Komponen yang ke dua exposure with control, dalam hal ini dengan adanya latihan gerakan fungsional yang diberikan melalui intervensi CFT maka pasien akan mendapatkan strategi untuk menormalkan postural dan perilaku pergerakan yang mereka anggap bahwa selama ini menyakitkan, ditakuti, atau dihindari. Sehingga dengan pendekatan ini dapat membangun kesadaran untuk melepaskan respon tubuh yang protektif. Perilaku postural dan gerakan yang baru kemudian diintegrasikan (Functional integration) dalam fungsi provokatif nyeri yang dinominasikan di setiap kegiatan terkait dengan tujuan mereka untuk menggeneralisasi pembelajaran dan membangun self-efficacy. Komponen yang terakhir mengenai lifestyle change, di mana dengan adanya perubahan gaya hidup individu dapat meningkatkan aktivitas fisik secara bertahap, dan fokus pada kebiasaan tidur yang baik, pengelolaan stres, dan strategi manajemen perawatan $\operatorname{diri}^{9}$.

Penelitian yang dilakukan oleh MeziatFilho, et al meneliti efektivitas CFT menyatakan bahwa terapi ini dapat mengurangi rasa nyeri dan keterbatasan fungsional. Intervensi kognitif ini dapat mengubah kepercayaan negatif pasien yang dihubungan dengan biomedis terintegrasi dengan manual terapi dan olahraga, hal ini penting diberikan untuk memungkinkannya mendapatkan kembali percaya diri pada tubuhnya dan kembali beraktivitas normal. Nyeri yang dirasakan pasien terdapat hubungan stress yang merupakan salah satu pemicu nyeri, sehingga faktor tersebut dapat memperkuat gerakan maladaptif, meningkatnya tingkat kepekaan ambang rasa nyeri dan keterbatasan fungsional. ${ }^{10}$ Konsep tersebut juga dijelaskan oleh Siska bahwa untuk menangani penderita nyeri hal yang harus dipahami bahwa pada umumnya nyeri dirasakan lebih keras jika terdapat juga kecemasan, depresi maupun kesepian. Hal ini terjadi pada penderiata NLBP, mereka merasakan nyeri yang lebih hebat jika dihindari oleh keluarga dan teman-temannya. Sebaliknya jika penderita nyeri ini diberikan kata-kata yang menentramkan dan menyenangkan maka rasa nyeri tersebut akan berkurang. ${ }^{11}$ Dalam hal ini, CFT merupakan intervensi yang mampu mengendalikan emosional individu terhadap rasa sakit, seperti rasa takut dan rasa sakit yang terkait dengan nyeri, dan konteks sosial saat ini. Selain itu, berkurangnya tingkat kecemasan juga dapat mengurangi nyeri fisik, karena otot menjadi tidak tegang sehingga nyeri dapat berkurang dan individu mampu melakukan aktivitas sehari-hari.

\section{Efek McKenzie dalam menurunkan disabilitas pada Non spesific Low Back Pain}

McKenzie dapat menurunkan disabilitas pada kasus nyeri punggung dikarenakan pada posisi ekstensi yang dipertahankan dalam waktu tertentu akan diperoleh peregangan pada jaringan lunak bagian ligamen anterior sehingga akan mengembalikan posisi spine pada posisi ekstensi. Hal ini dapat membantu menimbulkan dorongan discus ke posterior. Kemudian pada otot yang spasme akan terjadi pelemasan (rileksasi) oleh peregangan yang intermiten dan kontinyu terhadap otot antagonis. Pelemasan (rileksasi) ini terjadi karena adanya peregangan yang akan merangsang tendon golgi sehingga terjadi reflek rileksasi otot yang bersangkutan dan peregangan intermiten akan memperbaiki mikro sirkulasi oleh pumping action sehingga mengurangi iritasi pada saraf afferent yang menimbulkan reflek peningkatan tonus otot. Selanjutnya akan terjadi penekanan diskus ke sisi posterior sehingga didapatkan gerakan yang mendorong nucleus ke ventral. Akibatnya adanya gerak dinamis ekstensi yang dilakukan berulang dapat meningkatkan cairan discus dan corpus yang kemudian akan menurunkan viscositas nucleus pulposus ke posisi anterior dan dapat mengurangi iritasi terhadap jaringan sekitarnya. Dengan keadaan seperti ini nyeri akan menurun dan aktivitas fungsional dapat lebih ditingkatkan. ${ }^{12}$ 
Sejalan dengan penelitian yang dilakukan oleh Moldovan menunjukan hasil bahwa McKenzie Exercise lebih efektif dibandingkan Wiliam's Flexion Exercise dalam menurunkan nyeri punggung bawah. Prinsip latihan McKenzie adalah memperbaiki postur untuk mengurangi hiperlordosis lumbal. Sedangkan secara operasional pemberian latihan untuk penguatan otot punggung bawah ditujukan untuk merileksasikan otot, memperkuat otototot lumbosacral terutama otot dinding perut abdomen dan otot gluteus, meregangkan otototot yang memendek terutama otot-otot ekstensor punggung bawah, hamstring, dan otot quadratus lumborum, serta koreksi postur. ${ }^{13}$

\section{Cognitive Functional Therapy lebih baik dalam menurunkan disabilitas daripada McKenzie}

Nyeri pada NLBP secara luas diakui bahwa pengalaman nyeri bukan hanya pesan masuk tentang kerusakan jaringan. Sebaliknya, pengalaman rasa nyeri mencerminkan penilaian seseorang tentang seberapa berbahayanya input tertentu, atas dasar tidak hanya intensitas input tetapi juga pengalaman, keyakinan, dan faktor kontekstual sebelumnya dari orang tersebut (multidimensi). Hal ini tentunya terkait dengan apa yang disebut penilaian kognitif (cognitive appraisals) terhadap situasi-situasi yang mendatangkan stress, sehingga dengan pemberian CFT pasien mampu memanagemen nyeri dan keterbatasan fungsionalnya, membangun self-efficacy, kepercayaan diri, kemampuan beradaptasi dan memberikan harapan serta kesempatan untuk perubahan akibat nyeri yang dirasakan. ${ }^{14}$

Respon pikiran individu terhadap nyeri yang dirasakan dapat diasosiasikan dengan kemampuan coping individu menghadapi nyerinya (dimensi kognitif). Menurut Barkwell menyatakan bahwa nyeri yang dirasakan pasien merupakan suatu tantangan, maka nyeri lebih rendah dengan tingkat depresi yang rendah juga dan disertai dengan mekanisme coping yang lebih baik jika dibandingkan dengan pasien yang menganggap nyerinya adalah sebagai hukuman atau sebagai musuh. ${ }^{15}$

Dimensi afektif dari nyeri mempengaruhi respon individu terhadap nyeri yang dirasakanya. Dimensi ini indentik dengan sifat personal tertentu dari individu. Pasien yang mudah sekali mengalami kondisi depresi atau gangguan psikologis lainnya akan lebih mudah mengalami nyeri dibandingkan dengan pasien lainnya. Tingkat keparahan nyeri berhubungan signifikan dengan kondisi depresi individu yang mengalami nyeri kronik. Mereka juga menyatakan bahwa semakin berat nyeri yang dialami, maka semakin tinggi tingkat depresi individu tersebut. Sistem limbik merupakan tempat emosi diproses, memodulasi jumlah rasa sakit yang dialami untuk stimulus berbahaya yang diberikan. Rasa sakit dapat dilihat sebagai sebuah sinyal bahwa ada sesuatu yang salah di suatu tempat di dalam tubuh, sampai tercapai otak bagian emosional, di mana sinyal ini menjadi apa yang kita rasakan sebagai rasa sakit. Respons emosional terhadap rasa sakit melibatkan anterior cingulate gyrus dan ventral prefrontal cortex kanan. Sirkuit serotonin dan norepinefrin juga terlibat dalam modulasi rangsangan sensorik, yang mungkin mempengaruhi bagaimana depresi dan obat antidepresan memengaruhi persepsi nyeri. ${ }^{16}$

NLBP terjadi akibat adanya ketegangan otot, ligamen, bantalan antar tulang dan sendi serta psikogenik. Apabila otot tersebut mengalami ketegangan maka aktivitas akan terganggu. Semakin kuat dan sering otot mengalami ketegangan sehingga menimbulkan stress pada jaringan tersebut maka akan menstimulus nosiceptor sehingga semakin kuat pula aktivitas refleks ketegangan otot yang mengakibatkan nyeri. Melalui McKenzie maka dapat meningkatkan kekuatan dan penguluran otot-otot ekstensor dan fleksor sendi lumbosacralis dan dapat mengurangi nyeri. Latihan McKenzie mampu memperbaiki postur dengan mengurangi hiperlordosis lumbal. Sedangkan secara operasional pemberian latihan untuk penguatan otot punggung bawah ditujukan untuk otot-otot fleksor dan untuk peregangan ditujukan untuk otot-otot ektensor punggung. ${ }^{17}$

Sehubungan dengan efek CFT terhadap penurunan disabilitas, hasil penelitian ini sejalan dengan penelitian yang dilakukan oleh Fersum et al menyatakan bahwa CFT lebih efektif daripada Manual Therapy and Exercise (MT-EX) saja dalam menurunkan disabilitas 
pada Non-specific Low Back Pain. CFT menghasilkan penurunan jangka panjang dalam kecemasan dan depresi, dan rasa sakit terkait rasa takut saat bekerja dibandingkan dengan MT-EX. Hasil penelitian ini sangat bermanfaat dengan efek jangka panjang bagi prilaku individu yang berorientasi menargetkan keyakinan nyeri, pemulihan fungsional dan gaya hidup. ${ }^{18}$

\section{KETERBATASAN PENELITIAN}

Keterbatasan dalam penelitian ini adalah peneliti hanya mengambil dari kasusnya tetapi tidak mengontrol sampel dari pekerjaannya, termasuk aktivitas keseharian pasien di lingkungan kerja maupun tempat tinggal. Penelitian ini pada hasil jangka pendek sehingga hasil jangka panjang belum diketahui.

\section{SIMPULAN}

1. Cognitive Functional Therapy dapat menurunkan disabilitas pada penderita Non-specific Low Back Pain

2. McKenzie dapat menurunkan disabilitas pada penderita Non-specific Low Back Pain

3. Cognitive Functional Therapy lebih baik dalam menurunkan disabilitas dibandingkan dengan McKenzie pada penderita Non-specific Low Back Pain

\section{DAFTAR PUSTAKA}

1. Patrianingrum, M., Ezra, O., Eri, S. 2015. Prevalensi dan Faktor Risiko Nyeri Punggung Bawah di Lingkungan Kerja Anestesiologi Rumah Sakit Dr. Hasan Sadikin Bandung. Jurnal Anestesi Perioperative. 3 (1): 47-56

2. Fitrina, R. 2018. Low Back Pain (LBP). Direktorat Jenderal Pelayanan Keshatan. Kementerian Kesehatan Republik Indonesia. (serial online). Diakses pada tanggal 17 Januari 2019. Dikutip dari http://yankes.kemkes.go.id/read-low-backpain-lbp-5012.html

3. Bardin LD., King P., Maher CG. 2017. Diagnostic triage for low back pain: a practical approach for primary care. The Medical Journal of Australia. 3;206(6):268-273.

4. Balague, Mannion AF, Pellise F, Cedraschi C. Non-specific low back pain. 2012. National Library of Medicine National Institutes of Health. 4;379(9814):482-91

5. Heitz, C. A. M., Hilfiker, R., Bachmann L. M., Joronen, H., Lorenz, T., Uebelhart, D., Klipstein, Florian Brunner, A. 2009. Comparison of risk factors predicting return to work between patients with subacute and chronic non-specific low back pain: systematic review. European Spine Journal. 18.12:1829-1835.

6. Maher, Crish., Underwood, Martin., Buchbinder., Rachelle. 2017. Non-specific Low Back Pain. National Library of Medicine National Institutes of Health. LANCET. Feb 18;389(10070):736-747

7. Bunzli, S. 2016. Cognitive Functional Therapy for chronic low back pain: The patients' perspective. Pain Education. (serial online). May 27, 2016. Available from: http://www.pained.com/blog/2016/05/27/cognitivefunctional-therapy-for-chronic-low-backpain-the-patients-perspective/

8. Wahyuni, N. 2012. Perbedaan Efektivitas Antara Terapi Latihan William's Flexion dengan Mckenzie Extension Pada Pasien Yang Mengalami Postural Low BackPain. Majalah Ilmiah Fisioterapi Indonesia (MIFI) 
9. O'Sullivan, P. B., Caneiro, J. P., O'Keeffe, M., Smith, A., Dankaerts, W., Fersum, K., \& O'Sullivan, K. 2018. Cognitive Functional Therapy: An Integrated Behavioral Approach for the Targeted Management of Disabling Low Back Pain. National Library of Medicine National Institutes of Health. Physical Therapy. 98(5), 408-423

10. Meziat-Filho., N., Lima, M., Fernandez, J., Reis, F. J. J. (2018). Cognitive Functional Therapy (CFT) for chronic non-specific neck pain. Journal of Bodywork and Movement Therapies. 22(1), 32-36

11. Siska APP. 2010. Peranan Psikolog Dalam Menangani Penderita Nyeri Psikologi di Rumah Sakit. Fakultas Psikologi Universitas AKI. Majalah Ilmiah Informatika. Januari :1 (1): 4-5

12. Jumiati, J. 2015. "Penambahan Core Stabilization Exercise Lebih Menurunkan Disabilitas di Bandingkan dengan Penambahan Latihan Metode Mckenzie Pada Traksi Manipulasi Penderita Nyeri Pinggang Bawah Mekanik Di Kota Yogyakarta". (tesis). Denpasar: Program Pascasarjana Studi Fisiologi Olahraga Universitas Udayana

13. Moldovan, M. 2012. Therapeutic Considerations and Recovery in Low Back Pain: Williams versus McKenzie. Timişoara Physical Education and Rehabilitation Journal. Physical Education and Sport Faculty West University of Timișoara. Volume 5 Issue 9

14. Vibe, O'Sullivan P, Skouen JS, Smith A, Kvåle A. 2013. Efficacy of classificationbased cognitive functional therapy in patients with non-specific chronic low back pain: a randomized controlled trial. European Journal of Pain.17:916-928

15. Barkwell, D. 2005. Cancer pain: Voice of Ojibway people. Journal of Pain and Symptom Management. November. Volume 30, Issue 5, Pages 454-464

16. Vastag B. Scientists find connections in the brain between physical and emotional pain. 2003. National Library of Medicine. National Institutes of Health. JAMA;290(18):2389-90

17. McKenzie, R., \& May, S. 2003. The lumbar spine: mechanical diagnosis and therapy. Orthopedic Physical Therapy. Vol. 1:801-2

18. Fersum KV., Smith A., Kvåle A., Skouen JS., O'Sullivan P. 2019. Cognitive functional therapy in patients with nonspecific chronic low back pain-a randomized controlled trial 3 year followup. European Journal of Pain. Physiotherapy Research Group, Department of Public Health and Primary Health Care, University of Bergen, Norway. doi: 10.1002/ejp.1399 